\title{
CUANDO LA MUERTE VIENE A VISITARTE: EL PASO DE LA GRIPE DE 1918-1919 POR LA CIUDAD DE SEGOVIA
}

\author{
Rubén de la Fuente Núñez \\ Real Centro Universitario Escorial-María Cristina \\ Universidad Complutense de Madrid \\ Email: rfuente@rcumariacristina.com \\ ORCID iD: https://orcid.org/0000-0003-2833-6246
}

Recibido: 21 octubre 2019; Aceptado: 8 junio 2020

Cómo citar este artículo/Citation: Fuente Núñez, Rubén de la (2021) “Cuando la muerte viene a visitarte: el paso de la gripe de 19181919 por la ciudad de Segovia", Asclepio, 73(1): p344. https://doi.org/10.3989/asclepio.2021.10

RESUMEN: El presente artículo tiene como objetivo estudiar la gripe de 1918-1919 en Segovia, explicando su origen, evolución, mortalidad diferencial, profilaxis y las consecuencias más importantes que se derivaron de ella. Con este fin, se ha trabajado con la documentación existente en el Archivo Municipal de Segovia, las partidas de defunción del registro civil, estadística municipal, provincial y nacional, el Boletín Oficial de la Provincia y los principales periódicos segovianos. En primer lugar, nos centramos en la aparición de la epidemia, propagación, Ilegada a España y las víctimas causadas, atendiendo a su sexo, edad, procedencia, localización, estado civil y profesión. Las medidas preventivas y paliativas se analizan desde varios puntos de vista: organizativas, control de población, transportes, higiene, comercio, personal sanitario y dependencias hospitalarias. En cuanto a las secuelas que dejó en la provincia, se abordan desde dos enfoques: por un lado, el económico, aquéllas relacionadas con la escasez y subida de los precios de primera necesidad, y por otro, las que afectaron al normal desarrollo de la actividad en general.

PALABRAS CLAVE: Gripe 1918-1919; Epidemia; Segovia; Mortalidad; Profilaxis.

\section{WHEN DEATH COMES TO VISIT YOU: \\ THE PASSAGE OF THE FLU FROM 1918 TO 1919 THROUGH THE CITY OF SEGOVIA}

ABSTRACT: The objective of this article is to study the flu of 1918-1919 in Segovia, explaining its origin, evolutión, differential mortality, prophylaxis and the most important consequences. Several sources have been used for this article such as the existing documentation in the Municipal Archive of Segovia, the death certificates of the civil registry, municipal, provincial and national statistics, the Official Gazette of the Province and the main newspapers from Segovia. First, we focus on the appearance of the epidemic, spread, arrival in Spain and the death toll, according to their sex, age, origin, location, marital status and profession. Preventive and palliative measures are analyzed from several points of view: organizational, population control, transportation, hygiene, commerce, health-care staff and hospital units. The consequences of the pandemic of flu in Segovia are studied from two perspectives: on the one hand, the economic one, those related to the scarcity and rise of basic necessities prices, and on the other, those that affected the normal development of the general activity.

KEY WORDS: 1918-1919 Flu; Epidemic; Segovia; Mortality; Prophylaxis. 


\section{INTRODUCCIÓN}

En los meses de mayo y junio del año 1918 una epidemia invadió el territorio español produciendo una enorme mortalidad. La incubación era muy corta, el ataque repentino y por regla general los enfermos se curaban en tres o cuatro días. La enfermedad tenía el carácter de una infección aguda, con catarro inicial de faringe y vías respiratorias, fiebre elevada, sudores profusos y trastornos digestivos (Sánchez de Val, 1919).

A pesar de su gran impacto, la gripe, grippe, influencia o influenza, diferentes nombres con el que se conocía a la enfermedad (Erkoreka Barrena, 2006), no era desconocida en nuestro país. En 1580 ya hubo una gran epidemia que diezmó ciudades como Madrid o Barcelona, causando muertes tan ilustres como la cuarta esposa de Felipe II (Pérez Moreda, 1980). Posteriormente, reapareció con cierta fuerza a lo largo de los siglos XVIII y XIX, destacando el brote de 18891892, dejando un verdadero rastro de muerte a su paso (Betrán Moya, 2006).

Debido a su importancia, ha surgido una importante bibliografía. A nivel nacional, un primer acercamiento lo hizo el Boletín Mensual de Estadística Demográfica-Sanitaria (1915-1919), seguido de la aparición de otros estudios contemporáneos donde recogían los primeros datos de la epidemia (Porpeta Llorente, 1918; Sánchez del Val, 1919; García Durán, 1919; Sánchez Gozalbo, 1919). A partir de este momento, el tema de la gripe pasó a un segundo plano hasta prácticamente finales de siglo; carencia suplida con las investigaciones de referencia de Echeverri Dávila (1991 y 1993) y Porras Gallo (1994a). Con el cambio de centuria y la aproximación a su centenario, aparecieron otros estudios centrados en algunos temas específicos como fueron los sueros y vacunas utilizados (Porras Gallo, 2008), el papel de los sanitarios (Tuells y Montagud Penadés, 2010; Almudéver Campo, 2016) o ya en revisiones bibliográficas (González García, 2013; Porras Gallo y Davis, 2014; Porras Gallo, 2018; Echeverri Dávila, 2018), donde se recopilaban las principales investigaciones, daban diferentes enfoques y arrojaban nuevos resultados.

A nivel internacional, podemos destacar dos periodos historiográficos claros; en primer lugar, las primeras obras aparecidas al calor de la epidemia (Jorge, 1919; Frost, 1919; Tobías, 1920; Ministry of Health, 1920; Harvey Vaughan, 1921), en los que se recogían las primeras cifras de los países infectados o aquellos trabajos más ambiciosos, donde se intentaba dar una visión global de las consecuencias de la epidemia (Jordan, 1927). La segunda etapa tuvo lugar a raíz de la gripe de 1957 (González García, 2013), destacando los trabajos de Hoechling (1961), Crosby (1976), McNeill (1984) y, en especial, las obras de David Patterson y Gerald Pyle (1991). Más recientemente han sido publicados otros estudios en los que abarcaban diferentes características de la gripe, como el papel de los sanitarios, la respuesta de las autoridades o su mortalidad diferencial, destacando aquellas obras recopilatorias de carácter mundial (Phillips y Killingray, 2003; Trilla et al, 2008) y otras más enfocadas en el paso de la epidemia por diferentes países (Montañá Buchaca y Pujol i Ros, 1998; Langford, 2002; Guenel, 2004; Carbonetti, 2010; Martínez Martín et al, 2014; Rice, 2017; Burgués Roca, 2017; Botey Sobrado, 2017; Benítez, 2017).

A pesar de esta amplia bibliografía y de otras localizadas en algunas regiones españolas como son los casos de Madrid (Porras Gallo, 1997), Málaga (Carrillo Linares et al, 1985), Valencia (Martínez Pons, 1995), Navarra (Astigarraga Lizundia, 2006), el País Vasco (Erkoreka Barrena, 2006) o Cuenca (González García, 2012), entre otras, la historiografía ha dejado huérfana en este sentido a la provincia de Segovia. Por este motivo, el presente trabajo pretende llenar este hueco y contribuir con su estudio a conocer de una manera más cercana el comportamiento de la pandemia en un lugar de interior, permitiéndonos su comparación con otras zonas ya estudiadas y completar con ello, el mapa de la gripe de 1918 y 1919 en el territorio español. Para ello, nos hemos centrado en explicar la aparición de la epidemia, propagación, llegada a España y su mortalidad diferencial, deteniéndonos en el sexo, edad, naturaleza, localización, estado civil y profesión de las víctimas. Las medidas preventivas y paliativas se estudian desde varios apartados: organizativos, control de población, transportes, higiene, comercio, personal sanitario y dependencias hospitalarias. En cuanto a sus consecuencias, se abordan desde dos enfoques: por un lado, las económicas, aquéllas relacionadas con la escasez y subida de los precios de primera necesidad, y por otro, las que afectaron al normal desarrollo de la actividad en general.

Para la realización de esta investigación se ha trabajado con la documentación del Archivo Municipal de Segovia (AMS), destacando los Libros de Acuerdos del Ayuntamiento, Servicio de Higiene, Bandos Municipales y Junta Municipal de Sanidad. El cómputo de las víctimas ha sido extraído de las partidas de defunción del registro civil situadas en el Archivo del Juzgado Municipal (AJMS), revisando las muertes producidas desde el 1 de enero de 1918 hasta el 31 de mayo de 1919. También se ha hecho un seguimiento del Boletín Oficial de la Provincia de Segovia (BOPS), donde se reco- 
gía las principales medidas tomadas y el recorrido de la epidemia por la provincia. Asimismo, se ha consultado otras fuentes como son la prensa local y la estadística municipal, provincial y nacional.

\section{ORIGEN DE LA GRIPE DE 1918-1919}

Sobre la aparición de la epidemia, han surgido multitud de teorías, aunque la mayoría señalan a la primera Guerra Mundial. La efímera higiene en las trincheras, el hacinamiento de los combatientes, la escasez y mal estado de los alimentos, la precariedad de los uniformes y la falta de medios médicos y farmacológicos fueron el caldo de cultivo para la proliferación de este tipo de enfermedades (Burnet, 1967; Erkoreka Barrena, 2009). En este contexto, los aliados no dudaron en declarar que había sido un virus de origen alemán (Martínez Fiol, 2003). Tampoco el ejército estadounidense se salvaba, apuntando que fueron ellos quienes la trajeron al frente europeo procedente de un campamento de Kansas (Echeverri Dávila, 1993; Crosby 1976 y 2003) y de ahí, se fue extendiendo por el resto de Europa (Porras Gallo, 2018). Otros autores creen que la epidemia ya se había manifestado en las tropas inglesas en 1916-1917 o podría tener relación con la desarrollada en Francia en esos mismos años (Erkoreka Barrena, 2006). Otra teoría representa una híbrida de las anteriores, afirmando que la procedencia del virus habría que situarlo en China, de donde se trasladó a Filipinas y a través de ella, a los Estados Unidos (García Delgado et al, 1984). Relacionada con ésta, pero con un recorrido diferente, indicaba que su origen estaba en los 200.000 coolies chinos llegados a Francia en los primeros meses de 1918 para trabajar en la retaguardia (Betrán Moya, 2006). Independientemente de su origen exacto, la guerra contribuyó a una mayor propagación (Echeverri Dávila, 2018).

\section{SU LLEGADA A ESPAÑA Y EL MAL LLAMADO GRIPE ESPAÑOLA}

Si bien hay autores que avalan que la llegada del virus a la península Ibérica se produjo por el suroeste español y Lisboa (Patterson y Pyle, 1991; Erkoreka Barrena, 2006) ${ }^{1}$, las tesis más acertadas apuntan que su entrada tuvo lugar por la frontera francesa, debido al retorno de emigrantes que durante la contienda habían salido de España hacia el país vecino (García Delgado et al, 1984; Elexpuru Camiruaga, 1987; García Faria del Corral, 1995; Echeverri Dávila, 2003), repitiéndose esta circunstancia en el caso segoviano².

Otros autores coincidían en el origen, pero no en la procedencia de los portadores, afirmando que su introducción se debió al retorno de inmigrantes portugueses, bien en forma de trabajadores que volvían a su país desde Francia al verse privados de sus puestos de trabajo o bien como soldados lusitanos que regresaban del frente, pues fue en este contingente donde se detectaron los primeros casos de gripe maligna. Así en Irún, en septiembre de 1918, fue donde se cuantificaron varios casos infectados entre los inmigrantes (García-Faria Del Corral, 1995). Esta situación fue recogida por la prensa local, quiénes haciéndose eco de las medidas tomadas por las autoridades, procedieron a aislar a cualquier persona sospechosa ${ }^{3}$.

Independientemente de la procedencia de su llegada, lo que estaba claro es que su origen era foráneo. A pesar de ello, debido a la situación de neutralidad española, la ausencia de censura militar y el Real Decreto del 31 de octubre de 1901 por el que la gripe era enfermedad de declaración obligatoria, permitió una gran publicidad y la desafortunada denominación de gripe española (Porras Gallo, 1994a).

Una vez en España, se abrió un debate sobre la aparición de la enfermedad. En el caso de Madrid, por ejemplo, se relacionó el origen con las obras que estaban realizando en el metropolitano, que al remover las tierras se había liberado el virus ${ }^{4}$. Unos días más tarde se rechazó tal teoría, ya que se indicó que el microbio responsable estaba en la atmósfera. También se buscó en las harinas, el benzol, la fruta o en el agua (Porras Gallo, 1997). La confusión alcanzó tal magnitud, que incluso se llegó a responsabilizar al pegamento de los sellos y de los sobres (Losada Álvarez, 2003) o a la aspirina Bayer ${ }^{5}$. Y como no, algunos aprovecharon esta situación para atribuirla un tinte místico, afirmando que era un castigo divino, ya que entre sus víctimas se encontraban un gran porcentaje de personas de "mal vivir" y marginadas (Martínez Fiol, 2003).

\section{DESARROLLO DE LA EPIDEMIA}

A nivel nacional, la epidemia se desarrolló en tres fases, salvo algunas regiones que tuvieron un rebrote epidémico en 1920 (Erkoreka Barrena, 2006). En el caso de Segovia, hubo una primera oleada en la primavera de 1918, seguida de un repunte a finales del verano-otoño, volviendo en los primeros meses de 1919. Tal y como se refleja en la figura 1, la capital tuvo seis muertos por gripe en enero, pasando de los diez en cada uno de los cinco meses siguientes. Al igual que sucediera con otros núcleos españoles (Barreda Marcos, 2009), estos primeros casos fueron recogidos con normalidad ${ }^{6}$, debiéndose seguramente a una simple 
Desarrollo de la epidemia en Segovia capital

Fig. 1. Fuente: Partidas de defunción del registro civil de segovia del 1-I-1918 hasta el 31-V-1919- AJMS

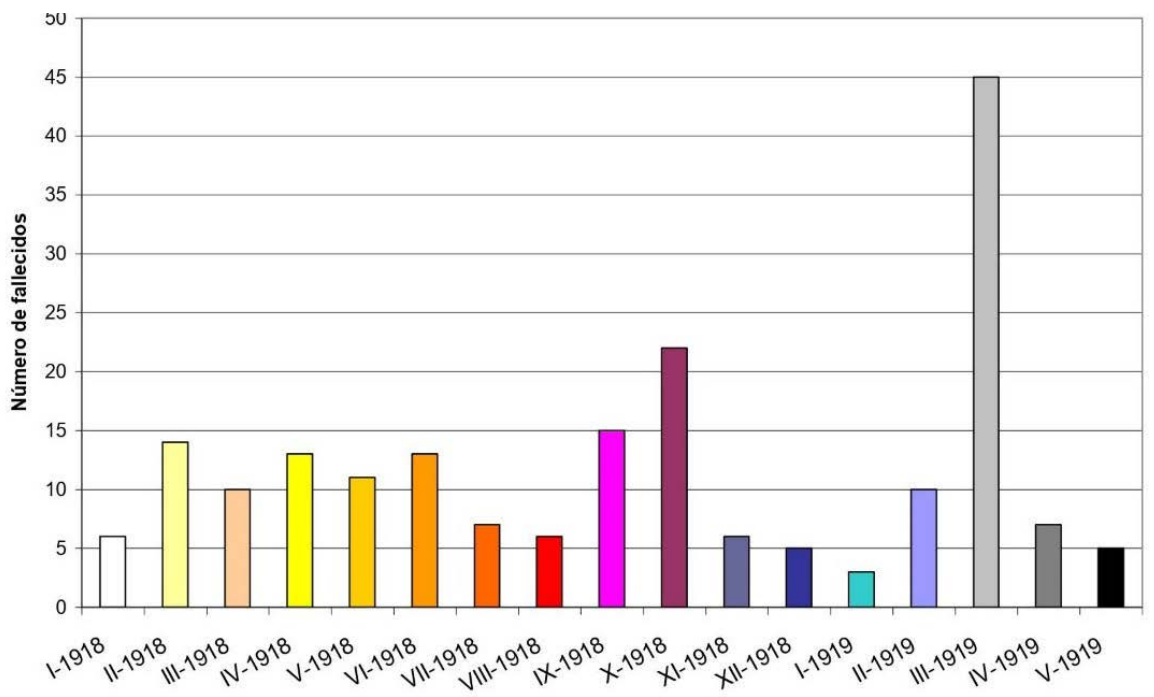

gripe estacional, aunque no se descarta la presencia del virus con anterioridad (Oxford et al, 2005).

El veintitrés de mayo, al igual que sucediera en otras provincias (González García, 2012), comenzó la primera ola de la epidemia, afirmando que eran muchos los atacados y que no había casa donde no se diera alguno ${ }^{7}$, causando un total de treinta y ocho fallecidos hasta el mes de agosto, siendo mayo y junio los meses más perjudicados con veinticinco víctimas. El Gobernador Civil emitió un comunicado avisando que ante la aparición de cualquier síntoma se diera conocimiento al inspector municipal de sanidad y se tomasen las medidas profilácticas oportunas ${ }^{8}$. Por si fuera poco, fue en esta etapa donde también surgieron casos de tifus en Palencia (Barreda Marcos, 2009), en Burgos y Logroño, pensando que el vehículo principal de propagación era el comercio de trapos viejos y ropas usadas, prohibiendo su circulación en las zonas infectadas ${ }^{9}$, aunque esta medida se haría extensiva a nivel nacional ${ }^{10}$. De esta forma, se debía hacer frente a una doble amenaza, la del tifus, y la gripe.

La evolución de la segunda ola de la epidemia siguió el mismo ritmo que en otras regiones (Echeverri Dávila 1993; Porras Gallo, 1994a; Erkoreka Barrena, 2006; González García, 2012), comenzando en septiembre y teniendo su punto álgido en octubre, sumando un total de treinta y siete bajas. Acabaría el año con seis fallecidos más en noviembre y cinco en diciembre. Esta nueva avalancha también se dejó notar en la provincia $^{11}$, donde pueblos como Nava de la Asunción, Ayllón o Mozoncillo pasaron de los 200 contagiados $^{12}$. A mediados de octubre, el número de municipios alcanzados ascendió a $90^{13}$, aumentando a 136 en la tercera semana ${ }^{14}$; a finales del mes, el número de personas infectadas fue de $11.000^{15}$.

En febrero de 1919, al igual que en otras localidades (Porras Gallo, 1997), volvieron a aparecer los primeros brotes. El desarrollo nacional fue dispar, mientras en algunas regiones esta oleada fue menos grave que en la anterior (Erkoreka Barrena, 2006; Porras Gallo, 2018), en otras tuvo mayor incidencia (González García, 2012). En el caso de Segovia capital fue el periodo de mayor mortalidad, alcanzando un total de cincuenta y ocho muertos, siendo marzo el mes más perjudicado con cuarenta y cinco defunciones, destacando los días diez y quince con siete y cinco óbitos cada uno. En el caso de la provincia, las noticias de cautela trasmitidas a la población los primeros días de febrero se cambiaron por otras alarmantes ${ }^{16}$, en el que de forma oficial regresaba la enfermedad. Marzo continuó sembrando de muerte a los municipios segovianos, hasta que, a finales de mes, la epidemia remitió. A pesar de ello, siguieron funcionando las Juntas Municipales de Sanidad para atender cualquier posible rebrote ${ }^{17}$. 


\section{MORTALIDAD DE LA GRIPE}

A nivel mundial, concretar el número de fallecidos a consecuencia de la gripe es bastante complicado. Los más de veinte millones calculados por Jordan (1927), han sido revisados por estudios posteriores fijándolos entre los cincuenta y cien millones (Burnet, 1979; Patterson y Pyle, 1991; Johnson y Mueller, 2002), cifras más altas que las causadas por la Primera Guerra Mundial. A nivel nacional, a los 168.249 muertos recogidos por la estadística $^{18}$, Echeverri Dávila (1993) los elevó hasta los 260.000-270.000, con una tasa de mortalidad del 13,03 por mil habitantes (Sánchez Fernández et al, 2019).

Por su parte, en el caso de Segovia, quizá porque la gripe se propagaba mejor entre la población que vivía de forma aglomerada, como podía ser el caso del hacinamiento de las grandes ciudades (Tobías, 1920), por las razones topográficas propias de esta ciudad, donde el clima era menos idóneo para su difusión, por la calidad de vida de sus habitantes ${ }^{19}$ o por otros motivos que desconocemos, el caso es que tuvo un comportamiento similar a capitales con porcentajes poblacionales semejantes (salvo Huesca), pero muy por debajo de las grandes urbes españolas ${ }^{20}$.

Como se observa en la figura 2 , el número de víctimas en la capital a consecuencia de la gripe o de sus complicaciones $^{21}$ del uno de enero de 1918 hasta el treinta y uno de mayo de 1919 fueron de 198 personas $^{22}$, para un censo de 15.300 y 15.401 respectivamente $^{23}$. Si acotamos a los meses de la epidemia, de mayo a diciembre de 1918 murieron ochenta y seis personas por gripe, siendo 493 los fallecidos en todo el año por diferentes causas; de enero a marzo de 1919 la gripe

Fallecidos por gripe y sus complicaciones en segovia capital del 1-I-1918 al 31-V-1919

Fig. 2. Fuente: Partidas de defunción del registro civil AJMS. *Se han agrupado en esta sección broquitis, bronquitis gripal, bronquitis aguda y crónica.

\begin{tabular}{cc}
\hline Causa de la muerte & Número de fallecidos \\
\hline Tuberculosis pulmonar & 31 \\
\hline Pulmonía gripal & 5 \\
\hline Pulmonía & 6 \\
\hline Neumonía & 4 \\
\hline Infección gripal & 1 \\
\hline Gripe & 34 \\
\hline Endocarditis gripal & 1 \\
\hline Congestión pulmonar & 3 \\
\hline Catarro pulmonar & 3 \\
\hline Bronquitis* & 39 \\
\hline Broncopulmonía gripal & 1 \\
\hline Broncopulmonía & 5 \\
\hline Bronconeumonía gripal & 14 \\
\hline Bronconeumonía & 50 \\
\hline Afección gripal & 1 \\
\hline Total & $\mathbf{1 9 8}$
\end{tabular}

causó cincuenta y ocho bajas para una mortalidad general de 526 , la cifra más alta de la década ${ }^{24}$. De todas las defunciones por gripe, en solo treinta y cuatro ocasiones era certificada ésta como causa de la muerte ${ }^{25}$, dato cercano a la estadística municipal ${ }^{26}$. En cuanto a la provincia, solamente en el mes de octubre de 1918 alcanzaron los 2.300 muertos por gripe, para una mortandad total de 6.469 para ese mismo año, también la más alta del último decenio ${ }^{27}$. Para el conjunto de la epidemia se calculan en 3.000 los óbitos $^{28}$, siendo la octava provincia más afectada de España (Echeverri Dávila, 1993).

En cuanto al número de fallecimientos por sexo, a nivel nacional la gripe tuvo mayor incidencia en mujeres que en hombres (Elexpuru Camiruaga, 1987; García-Faria del Corral, 1995; Echeverri Dávila, 2003). En algunas zonas este porcentaje fue equilibrado, como fueron los casos de Barcelona (Granero Xiberta, 1981) o Valencia (Martínez Pons, 1995). En cambio, en la capital segoviana hubo preponderancia de muertes masculinas sobre femeninas (56\% a 44\%), situación similar al caso de Cuenca (González García, 2012) o el País Vasco (Erkoreka Barrena, 2006). Este hecho no modificó el porcentaje de mortalidad segoviana por género, donde desde 1910 las muertes masculinas seguían superando a las femeninas ${ }^{29}$.

Esta mortalidad se centró en los grupos de edad de 0-4, 20-24 y 25-29 con treinta, veintidós y veintiún fallecidos respectivamente (ver figura 3 ), coincidiendo prácticamente con los datos expuestos a nivel nacional (García Delgado et al, 1984; Elexpuru Camiruaga, 1986; Palazón Fernando, 1991; Echeverri Dávila, 1993 y 2018; Fernández Fernández y Veiga Ferreira, 1995; García-Faria del Corral, 1995; Porras Gallo, 1997; García Palomar, 2003). La mortalidad entre los más pequeños era bastante explicable, debido principalmente a la ausencia de protección inmunitaria generada por olas anteriores (Echeverri Dávila, 2018) y a un desarrollo prematuro, en especial, inferior a doce meses, en el que el $53 \%$ de las víctimas tenía menos de un año, coincidiendo con la estadística nacional ${ }^{30}$.

En el caso de los grupos de edad que rondaban la veintena, también era preocupante y algo insólito en comparación con anteriores epidemias, siendo una singularidad de la gripe de 1918 (Echeverri Dávila, 2018). Además, fue 1918 el año de mayor número de víctimas comprendidas entre los 20 y 30 años de la década ${ }^{31}$. Por su parte, el descenso de mortalidad en los mayores adultos (40+), se achacó a que todas las personas pasaron la gripe de 1890 (Sánchez Gozalbo, 1919), cuestión en revisión, puesto que la memoria inmunológica desarrollada a muy temprana edad puede 
producir una respuesta inmunológica desajustada o no defensiva (Echeverri Dávila, 2018).

Otras de las consecuencias de esta preponderancia de muerte en ciertas edades se vieron reflejadas en el desarrollo total de la población. Un caso claro y evidente lo representó el número de matrimonios. Tanto en 1917 como en 1918, el número de enlaces en la provincia de Segovia se mantuvo estanco, 1.145 para el primero y 1.159 para el segundo. En cambio, un año después, la cifra ascendió a 1.540 nupcias $^{32}$. Una de las explicaciones más razonables fue la destrucción de matrimonios a consecuencia de la gripe (el $36 \%$ de las víctimas mayores de 15 años estaban casadas), dejando un número considerable de viudos y de viudas que volvieron a pasar por el altar.

El origen de los fallecidos fue mayoritariamente capitalino, aunque la unión de los procedentes de los pueblos de la provincia y del resto de España superaba a estos anteriores. La muerte se centró en los barrios de las afueras, los denominados como arrabales, aquellos situados en extramuros y cuyas viviendas tenían peor calidad $^{33}$, representando el $66,16 \%$ de los óbitos (ver figura 4); mortalidad ayudada por la presencia del establecimiento de beneficencia (De la Fuente Núñez, 2021). Estos porcentajes fueron bastante similares a la anterior epidemia de cólera (De la Fuente Núñez, 2016), estableciendo una relación palpable entre mortalidad (ya fuera la afección que fuese) y clase social.

Las profesiones ejercidas por parte de las víctimas destacaban claramente la de militares y jornaleros con doce y cuarenta y un efectivos respectivamente para los hombres y la de sus labores para las mujeres, debido al claro ocultamiento laboral en el que se en- contraban (De la Fuente Núñez, 2020), con un total de cuarenta y nueve. Los jornaleros, ya que su situación de por sí era bastante complicada, el denominado "síndrome de la miseria" (Echeverri Dávila, 2018), en caso de cualquier vicisitud tenían mayor posibilidad de ser arrastrados al abismo. Por su parte, en el sector castrense, es bastante significativo la repercusión que tuvo a consecuencia de la gripe, tanto a nivel local como nacional (Herrera Rodríguez, 1996). Además de la mala situación en la que se encontraba los cuarte$\operatorname{les}^{34}$, por su abandono, falta de higiene y hacinamiento de los soldados ${ }^{35}$, facilitando la circulación de los agentes patógenos (Echeverri Dávila, 2018), habría que sumar el desplazamiento de sus efectivos como causa de la propagación de la enfermedad (Porras Gallo, 1997; Echeverri Dávila, 2003) y el motivo de su elevada mortalidad (Porras Gallo, 1994a).

\section{PROFILAXIS DE LA GRIPE}

Aunque uno de los grandes problemas a la hora de combatir los efectos de la gripe es la frecuente mutación del germen que la causa, ya entonces se creía que los vehículos contaminantes residían en las finas gotitas o mucosidad expulsada mediante la tos, estornudos, la propia conversación o en la expiración normal, en la que hasta una distancia de treinta centímetros era proclive su contagio (Tobías, 1920), no descartando que cualquier objeto que hubiera estado en contacto con la epidemia fuera un vehículo de infección (Porpeta Llorente, 1918). Como sucediera con otras epidemias, una cosa era la teoría y otra la práctica, no impidiendo que la histeria colectiva volvería a apoderarse de la sociedad, desconociendo la procedencia y transmisión del virus, achacándolo al agua, la ropa, los

Fallecidos por gripe en segovia 1 enero 1918-31 mayo 1919

Fig. 3. Fuente: Partidas de defunción del registro civil de Segovia 1 enero 1918-31 mayo 1919 AJMS.

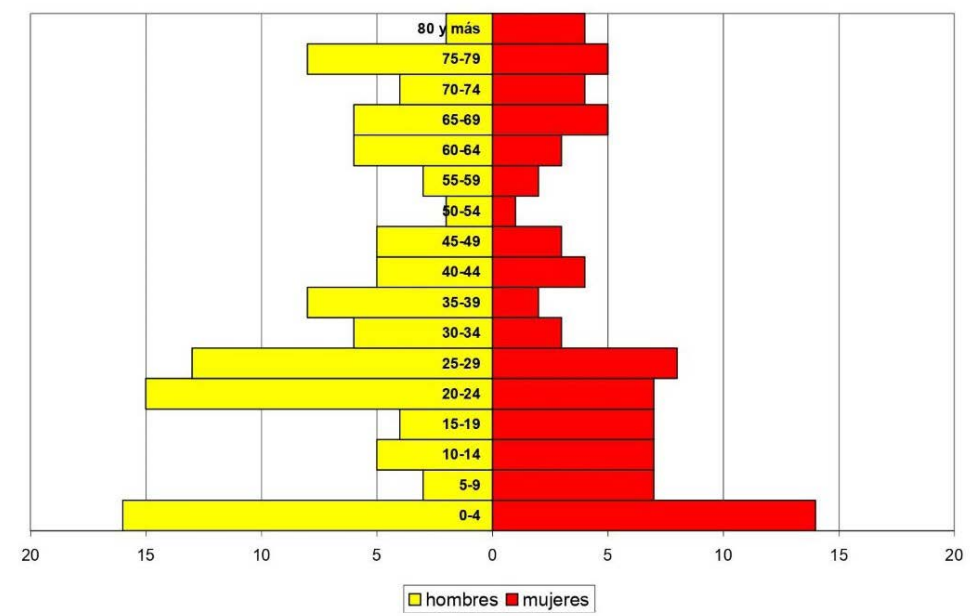


alimentos e incluso, a los propios recibos de la contribución ${ }^{36}$.

Para evitar su expansión, a nivel nacional se tomaron una serie de medidas orientadas a impedir su difusión o por lo menos acotarla, desde la inspección de mercancías y pasajeros que llegaban a las localidades (Herrera Rodríguez, 1996), prohibición de las aglomeraciones, aislamientos de los enfermos, limpieza y desinfección de ropa (Porpeta Llorente, 1918), aunque esta última eran menos importante, ya que el organismo supuestamente moriría fuera del cuerpo (Sánchez Gozalbo, 1919), hasta el control del consumo de alcohol, visita a prostíbulos (Carrillo Linares et al, 1985) o eliminación de aquellos focos de posible contagio, como podía ser el agua de las pilas bautismales (Fernández Fernández y Veiga Ferreira, 1995) ${ }^{37}$.

En lo que se refiere a la provincia segoviana en sí, el número y profundidad de las medidas aplicadas estuvieron relacionadas con la gravedad de las diferentes oleadas de gripe. Con la primera, las principales directrices fueron dirigidas a la higiene de las casas y de las calles, prohibiendo el barrido en seco (recomendando el uso de agua corriente) o sacudir la ropa por la ventana. Asimismo, se hizo un llamamiento para evitar aglomeraciones (no impidiéndolas) y se realizó un control de tránsito en las posadas ${ }^{38}$. Esta preocupación sobre el cuidado de la higiene y la limpieza de los domicilios era algo recurrente durante los siglos XIX y XX, ya que solamente la mitad de ellos reunían las condiciones higiénico sanitarias reglamentarias ${ }^{39}$.

Ya en el mes de septiembre, coincidiendo con la segunda oleada, llegaron una amplia batería de me- didas que continuaron prácticamente hasta el final de la epidemia. Para su estudio, las vamos a agrupar por secciones: organizativas, control de la población, transportes, higiene, comercio, animales, sanitarios y dependencias hospitalarias.

Primero, eran las Juntas Municipales y Provincial de Sanidad las encargadas del control y gestión de la epidemia, registrando los contagios y fallecimientos de cada municipio, siendo ayudadas por el Gobernador Civil, la Comisión Provincial y los diferentes alcaldes ${ }^{40}$. Contaron con un crédito extraordinario de 50.000 pesetas para poder auxiliar a los pueblos más necesitados, mandándoles toda la ayuda técnica y material posible ${ }^{41}$, aunque no fue así a pesar de las recomendaciones $^{42}$.

En cuanto al control de la población, toda persona o mercancía que llegaba al municipio era fumigaba ${ }^{43}$, en especial, a los reclutas al ser licenciados ${ }^{44}$, manteniéndoles aislados en los pueblos de origen, siguiendo las directrices del doctor Marañón ${ }^{45}$. Esta medida se haría extensiva al resto de la población que presentase algún síntoma de gripe ${ }^{46}$. Para evitar las aglomeraciones, se clausuró los espectáculos públicos, como eran los bailes ${ }^{47}$, el cine ${ }^{48}$ o el propio cementerio, reglamentando el trayecto que debían hacer las empresas fúnebres de la casa del difunto al camposanto, marcándolas el recorrido más corto y limitando el número de acompañantes ${ }^{49}$. De la misma forma, se ordenó el cierre de las escuelas, tanto privadas como públicas ${ }^{50}$.

En relación con los transportes, los vehículos destinados a este cometido debían de ser limpiados una vez que finalizara el servicio y colocar un rótulo con la

Fig. 4. Distribución espacial de la mortalidad por gripe en Segovia 1 enero 1918 - 31 mayo 1919. Fuente: Cada punto amarillo corresponde con un fallecido por gripe. Se ha excluido a 3 personas que su origen era desconocido y a 22 porque no concretaban su lugar de fallecimiento, indicando solamente el hospital, sin especificar hospital general, militar o de epidemias. Partidas de defunción del registro civil. AJMS, y usando como base, el plano de Segovia de 1920, escala 1:8.000. AMS.

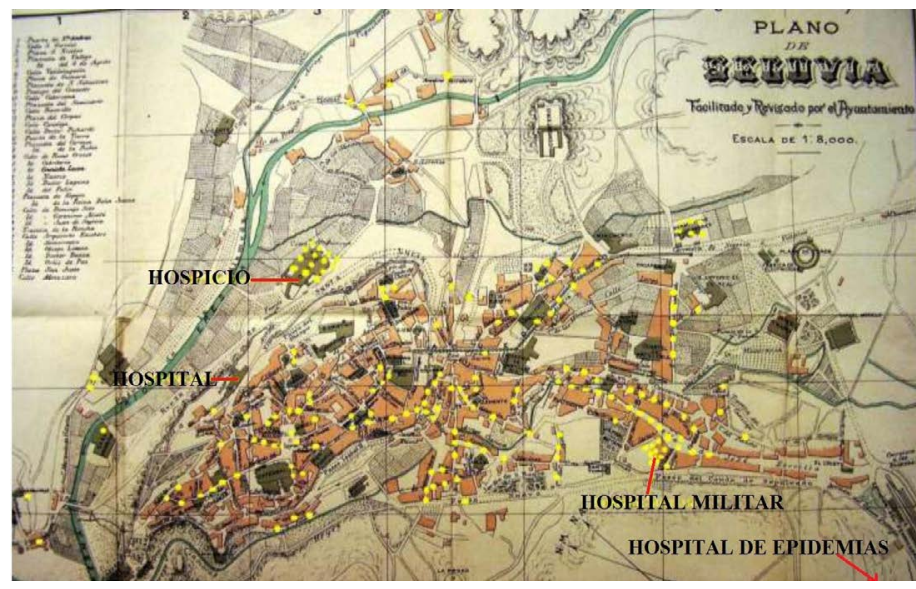


palabra "desinfectado"51. Durante el viaje, no podían ir herméticamente cerrados, sino que tenían que llevar algunas de las ventanillas abiertas ${ }^{52}$.

Desde el punto de vista de la higiene, se hizo hincapié en la limpieza de las casas, evitando los malos olores y la acumulación de basuras. Se incidió en la prohibición de verter desechos a la calle y en la instalación de retretes en los hogares, acometiendo las tuberías a la alcantarilla general. En caso de fallecimiento de algún familiar, el servicio de desinfección del municipio fumigaría todo el domicilio y las ropas del infectado se lavarían en el río Eresma, en un punto alejado de la ciudad $^{53}$.

Atendiendo al comercio, todas las mercancías debían estar cubiertas con gasas o fanales, permitiendo la circulación del aire, evitar el polvo y el contacto con los insectos. Una vez entregados al comprador, eran envueltas en papeles completamente blancos y limpios. Las básculas y cualquier instrumento que usaran para pesar, cortar y acondicionar los alimentos, tendrían que estar perfectamente desinfectados. Los comerciantes estaban en la obligación de facilitar a las autoridades las muestras que le fueran pedidas para su examen, analizando de forma diaria el pan y la leche ${ }^{54}$.

Por su parte, también se legisló sobre los animales dedicados al consumo, quedando prohibido la existencia de cerdos, conejos, gallinas..., en el interior de la población, sacrificar reses de ninguna clase en casas particulares, la entrada de carnes muertas o los depósitos de pieles frescas, huesos o astas ${ }^{55}$. Para verificar el cumplimiento de todas estas medidas, se crearon policías civiles sanitarios. Eran un cuerpo de voluntarios provistos de un carnet identificativo y su finalidad era simplemente supervisora ${ }^{56}$.

En cuanto al personal sanitario, se dio instrucciones precisas para el cumplimiento de sus funciones, informando de cualquier contagio o fallecimiento a consecuencia de la gripe, extremando la higiene y desinfección, sobre todo, de boca y las fosas nasales, recomendando el uso de escupideras provistas de líquidos antisépticos. Además, se les pagó un plus de 200 pesetas por sus servicios (aunque algunos de los municipios tardaron en abonar) ${ }^{57}$ y se les otorgaría el derecho de viudedad a sus parejas a todos aquellos médicos muertos en acto de servicio ${ }^{58}$, como después se comprobó ${ }^{59}$. Además, se anunciaba la creación de una plaza de médico de epidemias mientras fuese necesario. El facultativo acudiría al pueblo que se le requiriese, ofreciéndole una remuneración diaria de quince pesetas más otras veinticinco en concepto de dietas. Para su transporte, se le proporcionaría un medio de locomoción ${ }^{60}$. Esta medida resultaría insuficiente una vez empezada la epidemia debido al número de pueblos que requirieron sus servicios ${ }^{61}$.

A nivel de infraestructuras, se creó un hospital de epidemias en las afueras de la ciudad, situado en el lugar denominado de Buenavista, en la carretera de Hontoria, aunque sus condiciones no eran las más adecuadas para atender a los enfermos, como después se demostró (Garrote Díaz, 2001). Otros de los hospitales utilizados fueron el militar, donde en 1918 se trataron a noventa y siete infectados, de los que once fallecieron $^{62}$ y el general de la ciudad, el de la Misericordia. Para ayudar al traslado de enfermos, se aumentó el número de camilleros ${ }^{63}$.

Respecto a la actuación de las autoridades y la eficacia de las medidas tomadas, ha habido una amplia bibliografía a nivel nacional valorando sus principales acciones (Echeverri Dávila 1991 y 1993; Porras Gallo, 1994a, 1994b y 2018; Herrera Rodríguez, 1996; Astigarraga Lizundia, 2006; Blacik, 2009; González García, 2012). En el caso de Segovia, la variedad y el número de las ordenanzas expuestas y su comparativa con otras zonas, nos dan una imagen de su respuesta, en la que parece ser, hicieron todo aquello que los exiguos medios les permitían. La falta de mejores resultados fueron más consecuencia de los problemas generalizados del país, a nivel organizativo, económico o sanitario (Blacik, 2009; Porras Gallo, 2008 y 2018), que a la falta de celo de sus gobernantes, sumado a los problemas endémicos que venía arrastrando la provincia desde el siglo XIX, tanto a nivel de infraestructuras, de medios como de recursos (De la Fuente Núñez, 2016), demostrando la inoperancia de las autoridades locales para hacer frente por sí solos a estas catástrofes.

\section{TRATAMIENTOS DE LA GRIPE $Y$ REMEDIOS ALTERNATIVOS}

Con la epidemia en marcha, los médicos recurrieron a una amplia batería de medidas terapéuticas, aunque conscientes muchos de ellos de que no existía un tratamiento que por sí solo fuera eficaz. En primer lugar, se intentó hacer una terapia sintomática: aspirina y sales de quinina para la fiebre, arsenicales y glicerofosfatos para la astenia y codeína para la tos rebelde. Otros, al observar que algunos pacientes mejoraban después de una hemorragia nasal, consideraron que las sangrías podrían producir el mismo efecto. También se aplicó una vacuna mixta compuesta del bacilo de Pfeiffer, neumococos y estreptococos. Para los casos graves se utilizó sueros antineumocócicos y anties- 
treptocócicos, aunque con resultados tan desiguales, que casi ningún médico se atreviera a recomendarlos (Porras Gallo, 2008).

A nivel provincial, el doctor segoviano Antonio García Tapia desarrolló varios tratamientos. Proponía mezclar sal común, bicarbonato y biborato de sosa. También recomendaba una disolución de gomenol en aceite de olivas. La combinación de estos productos serviría para la desinfección y prevención de las fosas nasales y faringe. Tal fue el éxito, que se repartieron dosis por toda la provincia obteniendo excelentes resultados (Álvaro Gómez, 2008).

Fuera del ámbito médico, apareció una amplia batería de productos alternativos destinados a paliar los efectos de la gripe. A los anunciados de forma habitual, como eran las pastillas Crespo, las píldoras Bolívar o el jarabe Orive, donde curaban la bronquitis, el asma y la tuberculosis ${ }^{64}$, surgieron otros, destacando el jabón Zotal, que afirmaba que la epidemia reinante solo se impedía desinfectando con dicho producto ${ }^{65}$; el yodo en gotas, en el que además de ser un método eficacísimo y barato era recetado para combatir la debilidad y la desnutrición ${ }^{66}$; el coñac Carmela y el jerez Quinado San Andrés, siendo los específicos más recomendados para evitar y luchar contra la enfermedad ${ }^{67}$ o las pastillas Quit, el mejor purificador de las vías respiratorias ${ }^{68}$. Además de estos anteriores, los industriales de la ciudad comenzaron a crear su propia línea de productos profilácticos que, aprovechando los momentos de mayor agitación social, vendieron a unos precios abusivos ${ }^{69}$.

\section{CONSECUENCIAS DE LA GRIPE}

Al igual que sucediera con la anterior epidemia de cólera de 1885 (De la Fuente Núñez, 2016), el paso de la gripe por Segovia provocó una serie de secuelas que modificaron el normal desarrollo de la actividad en general, en especial, aquellas relacionadas con la escasez de productos y la consecuente inflación. Ya en el mes de marzo de 1918, el Gobernador Civil de la provincia hizo un llamamiento a los alcaldes de los diferentes municipios para que vigilasen el precio de los productos de primera necesidad, ya que a pesar de la Real Orden con fecha de tres de enero de 1917 donde no se podía subir el importe de los alimentos sin que previamente el comerciante o el gremio hubiera formulado dicha instancia, el valor de la carne y de otros artículos había aumentado ${ }^{70}$. También prohibió la venta de trigo a una tarifa superior a la tasa, castigando con multas que rondaban entre las 500 y las 5.000 pesetas $^{71}$. Asimismo, se controló el precio del arroz, debido a su encarecimiento ${ }^{72}$.
Durante el mes de abril, los precios siguieron aumentando. Para frenar la subida de la carne, se permitió que la matanza del cerdo continuase durante los meses siguientes, ya que, hasta entonces, el sacrificio estaba regulado exclusivamente al periodo comprendido entre noviembre y marzo ${ }^{73}$.

Asimismo, el consumo de algunos alimentos se disparó, aquellos que pensaban propicios para luchar contra la enfermedad como eran los limones, los ajos o la propia leche, provocando escasez y, con ello, importes prohibitivos ${ }^{74}$. Se intervino el aceite, fijando el precio máximo al que se podía vender; de esta forma, prevenían la aparición de los acaparadores y favorecían a las clases populares, que estaban siendo las más perjudicadas por el paso de la epidemia ${ }^{75}$. Este incremento también se dejó notar en los medicamentos, haciendo un llamamiento a los médicos para un uso racional de los mismos, sobre todo, con el suero antidiftérico, aplicándose exclusivamente en aquellos casos de neumónicos graves, no prodigando su uso a cualquier forma de gripe, como se estaba haciendo hasta ese momento ${ }^{76}$.

Además de este incremento de los precios, se empezó a notar su carestía. Para luchar contra ella, se prohibió a los ganaderos que alimentaran a los animales con trigo o harinas, en sustitución de sus correspondientes piensos ${ }^{77}$, se persiguió a aquellos acaparadores que se hacían con el control de los productos, se liberó el tránsito de mercancías por toda la provincia ${ }^{78}$ y se procedió al reparto de alimentos básicos entre los más pobres, como fue el caso la leche ${ }^{79}$.

Otras de las consecuencias, fue la alteración de la actividad diaria. En primer lugar, hemos comprobado como el ramo militar tuvo bastante personal encamado, teniendo problemas para cubrir la ausencia de sus efectivos. Tampoco se escapó la administración segoviana, como fue el caso de la Diputación Provincial, quiénes fueron suspendiendo día a día sus reuniones a consecuencia de la enfermedad ${ }^{80}$; la clausura de la estación telegráfica del pueblo de Sepúlveda ${ }^{81}$ o la confección y reparto del periódico diario ${ }^{82}$. También la industria sufrió los envites de la epidemia, en el que sus obreros eran reticentes a abandonar su casa por miedo al contagio ${ }^{83}$. De la misma forma, afectó a las escuelas o centros de enseñanza, retrasándose el inicio del curso escolar en unas y en otros, simplemente suspendiéndose. Y como no, los bares, restaurantes, teatros o cines tuvieron que cerrar sus puertas de forma intermitente para intentar frenar los estragos de la gripe, provocando junto a la escasez de los alimentos, un aumento de la crispación social. 
También se vieron alterados los domicilios de la población, pasando de hogares de vida a nidos de muerte. En el momento en el que cualquier miembro de la familia era portador del virus, el resto de sus seres queridos tenían bastantes posibilidades de contagiarse y, en consecuencia, de morir. La prensa local fue testigo de las víctimas dadas en las mismas casas, falleciendo en idénticos días o en fechas muy seguidas. Un ejemplo de esta macabra estadística la recogió El Adelantado de Segovia en la portada del día ocho de octubre de 1918. Sucedió en el pueblo segoviano de Aragoneses; en él vivía la familia Martín Borregón. El día dos de octubre de 1918 falleció David Martín Borregón a los dieciséis años. El resto de la familia, después de regresar del cementerio de dar sepultura a su hijo, se dirigieron a su casa para cuidar de Samuel, su otro hijo, quién también estaba enfermo. Todas las medidas fueron estériles, muriendo el día tres a los veinticinco años, al día siguiente que lo hiciera su hermano. El hogar se quedaba vacío y sus padres, viendo como la epidemia se cebaba con ellos, nos les quedaban más remedio que velar por sus vidas. Cuando la familia empezaba a asimilar la pérdida de sus seres más queridos, la muerte volvió a visitarles, en este caso se llevó a la madre, Estefania Borregón Gozalo, falleciendo el cinco de octubre, tres y dos días después que lo hubieran hecho sus dos hijos. Ricardo Martín Gómez, esposo de esta última y padre de los dos anteriores, maldecía al destino a la vez que intentaba luchar por su vida ${ }^{84}$.

\section{CONCLUSIONES}

Independientemente del origen, transmisión y vía de entrada de la gripe al territorio español, el caso fue, que la provincia de Segovia también se vio afectada. La evolución de la epidemia tuvo un desarrollo similar al del resto del país, aunque a diferencia de otras regiones, su tercera ola fue más mortal que las dos anteriores.

Con la llegada de las primeras noticias, las autoridades procedieron a implementar un amplio abanico de medidas en función de la gravedad. Las principales líneas de actuación estuvieron dirigidas especialmente a la prevención, sobre todo, higiene, desinfección y aislamiento. Con la epidemia en la ciudad, todos estos esfuerzos resultaron inútiles, más que por el número y eficiencia de las medidas, por la falta de profundidad y recursos para implementarlas. Las infraestructuras de los municipios, el número de sanitarios, los escasos medios médicofarmaceúticos y la precariedad de la población, hicieron el resto, reflejando la indefensión en la que se encontraba los vecinos, sintiéndose impotentes cuando la epidemia llamaba a sus puertas y se llevaba a sus seres más queridos.

La enfermedad recayó en los grupos más vulnerables de la sociedad, aquellos situados en los barrios más humildes, demostrando una vez más ser una epidemia clasista, estando evidente la relación entre mortalidad y grupo social. La ocupación de jornaleros de la gran mayoría de los hombres fallecidos, atestiguan esta realidad. El otro grupo, el de los militares, nos arroja la otra gran consecuencia, la causa-efecto entre el sector castrense y la propagación de la enfermedad.

La mayor pandemia de los últimos años dejó mella en la población segoviana, influyendo en el cómputo general de muertes tanto a nivel local como provincial, siendo 1818 y 1919 los años de mayor mortalidad de la década. La enfermedad incidió más en los hombres que en las mujeres, situación excepcional en comparación con el resto de las localidades españolas. Los grupos de edades más perjudicados fueron prácticamente los mismos, repercutiendo en el número de matrimonios de los años posteriores.

La actividad general de la provincia se vio afectada por el paso de la epidemia. A nivel económico, además de su paralización por la clausura de bares, teatros y comercios, la suspensión del funcionamiento de las escasas fábricas, cierre de estaciones telegráficas o del periódico, las consecuencias más importantes tuvieron que ver con la escasez de algunos productos y la subida generaliza de los precios, evidenciando una vez más la relación entre catástrofe epidemiológica y secuelas económicas. A diferencia de la anterior, la del cólera, la gripe vino acompañada de un aliciente internacional, la Primera Guerra Mundial, provocando que estas fluctuaciones y escasez ya vinieran marcadas de antes y con ello, una mayor acentuación. 


\section{NOTAS AL FINAL}

1 Casualmente esta teoría coincide con que fueron Extremadura, Andalucía y el sur de la Meseta Central las zonas más afectadas por la primera oleada de gripe.

2 "La emigración en Segovia", en El Adelantado de Segovia, 4 de febrero de 1918, número 4.608, p. 1.

3 El Adelantado de Segovia, 18 de septiembre de 1918, número 4.794 , pp. $1-2$

4 Noticia recogida por El Adelantado de Segovia, 24 de mayo de 1918, número 4.697, p. 1.

5 Esta última más por el antigermanismo de las potencias aliadas que por razones médicas, llegando a afirmar que los alemanes habían difundido esta enfermedad por medio de la aspirina.

6 El Adelantado de Segovia, 5 de abril de 1918, número 4.656, p. 1.

7 El Adelantado de Segovia, 23 de mayo de 1918, número 4.696, p. 2.

8 El Adelantado de Segovia, 4 de junio de 1918, número 4.705, p. 1.

9 BOPS, 12 de julio de 1918, número 83, p. 1.

10 BOPS, 21 de octubre de 1918, número 126, p. 1.

11 El Adelantado de Segovia, 1 de octubre de 1918, número 4.804, p. 1.

12 El Adelantado de Segovia, 26 de septiembre de 1918, número 4.800 , p. 2, 8 de octubre de 1918, número 4.810, p. 2 y 12 de octubre de 1918, número 4.814, p. 2.

13 El Adelantado de Segovia, 14 de octubre de 1918, número 4.815 , p. 2.

14 El Adelantado de Segovia, 21 de octubre de 1918, número 4.821, p. 2.

15 El Adelantado de Segovia, 29 de octubre de 1918, número 4.827, p. 1.

16 El Adelantado de Segovia, 7 de febrero de 1919, número 4.907, p. 1.

17 BOPS, 9 de abril de 1919, p. 1.

18 "Resumen general de las defunciones clasificadas por causas de muerte y por grupos de edades", en Movimiento Natural de la Población 1918-1919, Fondo documental del Instituto Nacional de Estadística (FDINE).

19 El Adelantado de Segovia, 20 de febrero de 1919, p. 1.

20 "Defunciones, clasificadas por causas de muerte y por capitales. Resumen anual. Año 1918", en Anuario 1918. FDINE, pp. 604-605.

21 Tuberculosis pulmonar, neumonía, bronquitis, bronconeumonía, pulmonía y los diferentes términos como afección o infección gripal, bronconeumonía gripal o catarro pulmonar con que los médicos certificaban la defunción.

22 AJMS. Partidas de defunción del registro civil de Segovia 1918-1919.

23 "Población calculada de las capitales de provincia 19111919", en Anuario de 1919, FDINE.

24 "Defunciones ocurridas en las capitales de España. Años 1909-1919", en Anuario 1919, FDINE.

25 AJMS. Partidas de defunción del registro civil de Segovia 1918-1919.
26 De esto modo queda constatado como la estadística oficial solo recogen las cifras de óbitos por gripe, no de sus complicaciones o derivaciones.

27 "Defunciones clasificadas por provincias y sexos. 19111921", en Anuario 1921-1922, FDINE.

28 El Adelantado de Segovia, 27 de noviembre de 1918, número 4.847, p. 1.

29 "Defunciones, clasificadas por provincias y sexos. Años 1910-1920", en Anuario 1920, FDINE.

30 AJMS. Partidas de defunción del registro civil de Segovia 1918-1919 y "Mortalidad infantil de ambos sexos, en cada uno de los cuatro primeros años de edad en el período de 1906-1925 en toda la Nación”, en Anuario 1924-1925, FDINE.

31 "Defunciones clasificadas por la edad de los fallecidos. Años 1912-1921", en Anuario 1921-1922, FDINE.

32 "Matrimonios, abortos, nacimientos y defunciones en la provincia de Segovia 1901-1949", en Anuario 1949, FDINE.

33 AMS. Servicio de higiene. Expedientes 110-1, 110-2 y 111-1.

34 El Adelantado de Segovia, 18 de septiembre de 1918, número 4.794, pp. 1-2.

35 El Adelantado de Segovia, 23 de septiembre de 1918, número 4.797, p. 1.

36 El Adelantado de Segovia, 28 de mayo de 1918, número 4.700, p. 1.

37 En el caso de Segovia, solo se recomendó a los párrocos cambiar el agua de forma frecuente, no impidiendo su uso. AMS. Libro de acuerdos del Ayuntamiento. Octubre 1918.

38 AMS. Libro de acuerdos del Ayuntamiento. Mayo-Junio 1918.

39 AMS. Servicio de higiene. Expedientes 110-1, 110-2 y 111-1.

40 BOPS, 19 de septiembre de 1918, número extraordinario.

41 BOPS, 17 de octubre de 1918, número extraordinario, p. 1.

42 BOPS, 22 de noviembre de 1918, número 140, p. 2.

43 El Adelantado de Segovia,14 de octubre de 1918, número 4.815, p. 1.

44 El Adelantado de Segovia, 24 de septiembre de 1918, número 4.798, p. 1.

45 El Adelantado de Segovia, 24 de mayo de 1918, número 4.697, p. 1.

46 BOPS, 7 de octubre de 1918, número 120, p. 1.

47 El Adelantado de Segovia, 24 de septiembre de 1918, número 4.798, p. 1.

48 El Adelantado de Segovia, 26 de septiembre de 1918, número 4.800, p. 2.

49 El Adelantado de Segovia, 18 de octubre de 1918, número 4.819, p. 1 y 22 de octubre de 1918, p. 1.

50 El Adelantado de Segovia, 28 de septiembre de 1918, número 4.802, p. 2.

51 AMS. Extracto de los veintiocho puntos del bando municipal. Libro de acuerdos del Ayuntamiento. Octubre 1918.

52 BOPS, 11 de octubre de 1918, número 122, p. 1.

53 AMS. Extracto de los veintiocho puntos del bando municipal. Libro de acuerdos del Ayuntamiento. Octubre 1918.

54 AMS. Extracto de los veintiocho puntos del bando municipal. Libro de acuerdos del Ayuntamiento. Octubre 1918. 
55 AMS. Extracto de los veintiocho puntos del bando municipal. Libro de acuerdos del Ayuntamiento. Octubre 1918

56 El Adelantado de Segovia, 10 de octubre de 1918, número 4.812, p. 1

57 BOPS, 6 de enero de 1919, número 3, p. 1.

58 El Adelantado de Segovia, 11 de octubre de 1918, número 4.813, p. 2.

59 La Tierra de Segovia, 19 de agosto de 1919, número 81, p. 4 y BOPS, 27 de noviembre de 1918, número 142, p. 1.

60 BOPS, 17 de octubre de 1918, número extraordinario, p. 1.

61 El Adelantado de Segovia, 30 de septiembre de 1918, número 4.803, p. 2.

62 Tres lo hicieron en mayo, uno en agosto y siete en septiembre de 1918. AJMS. Partidas de defunción del registro civil de Segovia 1918-1919.

63 El Adelantado de Segovia, 14 de octubre de 1918, número 4.815, p. 1.

64 El Adelantado de Segovia, 30 de enero de 1918, número 4.604, p. 4

65 El Adelantado de Segovia, 30 de septiembre de 1918, número 4.803, p. 3.

66 El Adelantado de Segovia, 19 de octubre de 1918, número 4.820, p. 2.

67 El Adelantado de Segovia, 22 de octubre de 1918, número 4.822 , p. 2.

\section{BIBLIOGRAFÍA}

Almudéver Campo, Laura (2016), La epidemia de gripe de 1918 y los profesionales de enfermería. Análisis a través de la prensa española, Tesis Doctoral, Universidad de Valencia.

Álvaro Gómez, Carlos (2008), Crónicas retrospectivas. Lugares, vivencias y sucesos en la Segovia de nuestros abuelos, Segovia, Caja Segovia.

Astigarraga Lizundia, José Ignacio (2006), La pandemia de gripe de 1918 en Navarra, (Tesis Doctoral), Universidad del País Vasco.

Barreda Marcos, Pedro Miguel (2009), "Palencia cuando la gripe de 1918", Publicaciones de la Institución Tello Téllez de Meneses, 80, pp. 309-339.

Benítez, Pablo (2017), "Gripe Española de 1918 en El Salvador", Americanía: revista de estudios latinoamericanos de la Universidad Pablo de Olavide de Sevilla, 6, pp. 53-76.

Betrán Moya, José Luis (2006), Historia de las epidemias en España y sus colonias. 1348-1919, Madrid, La Esfera de los Libros.

Blacik, Victoria (2009), "Críticas al Estado español durante la epidemia de gripe de 1918", Ayer, 75, pp. 247-273.

Boletín Mensual de Estadística Demográfica-Sanitaria, (19151919), Madrid.

Boletín Oficial de la Provincial de Segovia, (1918-1919).
68 El Adelantado de Segovia, 6 de noviembre de 1918, número 4.834 , p. 3

69 El Adelantado de Segovia, 23 de octubre de 1918, número 4.823, p. 1.

70 BOPS, 6 de marzo de 1918, número 28, p. 1.

71 BOPS, 8 de marzo de 1918, número 29, página extraordinaria.

72 BOPS, 22 de marzo de 1918, número 35, p. 1

73 BOPS, 1 de abril de 1918, número 39, p. 1.

74 BOPS, 22 de noviembre de 1918, número 140, p. 2.

75 BOPS, 17 de mayo de 1918, número 59, pp. 1 y s.

76 BOPS, 25 de octubre de 1918, número 128, p. 1.

77 BOPS, 4 de octubre de 1918, número 119, p. 1.

78 BOPS, 18 de diciembre de 1918, número 151, p. 1.

79 BOPS, 22 de noviembre de 1918, número 140, p. 2.

80 BOPS. En especial, los meses de septiembre a diciembre.

81 El Adelantado de Segovia, 10 de octubre de 1918, número 4.812 , p. 2.

82 El Adelantado de Segovia, 28 de mayo de 1918, número 4.700, p. 1.

83 El Adelantado de Segovia, 30 de octubre de 1918, número 4.828 , p. 2.

84 El Adelantado de Segovia, 8 de octubre de 1918, número 4.810 , p. 1

Botey Sobrado, Ana María (2017), "La tardía epidemia de influencia o gripe española y sus desenlaces en Costa Rica (19181920)", Americanía: revista de estudios latinoamericanos de la Universidad Pablo de Olavide de Sevilla, 6, pp. 77-109.

Burgués Roca, Sandra (2017), "La Pandemia de Gripe en Uruguay (1918-1919), Americanía: revista de estudios latinoamericanos de la Universidad Pablo de Olavide de Sevilla, 6, 2017, pp. 167-206.

Burnet, Macfarlane (1967), Historia de las enfermedades infecciosas, Madrid, Alianza.

Burnet, Macfarlane (1979), "Portraits of viruses: influenza virus A", Intervirology, 11 (4), pp. 201-214.

Carbonetti, Adrián (2010), "Historia de una epidemia olvidada: La pandemia de gripe española en la argentina, 1918-1919", Desacatos, 32, pp. 159-174

Carrillo Linares, Juan Luis; Castellanos Guerrero, Jesús; Ramos Palomo, María Dolores (1985), Enfermedad y gripe social: la gripe en Málaga 1918, Málaga, Universidad de Málaga.

Crosby, Alfred W. (1976), Epidemic and peace 1918, Greenwood.

Crosby, Alfred W. (2003), American's Forgotten Pandemic. The Infuenza of 1918, Cambridge University Press.

De la Fuente Núñez, Rubén (2016), La ciudad dependiente: el lento caminar de una ciudad de interior. Segovia 1860-1930, (Tesis Doctoral Inédita), Universidad Complutense de Madrid. 
De la Fuente Núñez, Rubén (2020), "El mercado de trabajo femenino en una ciudad de interior. Segovia 1860-1905", Investigaciones históricas: Época moderna y contemporánea, 40, pp. 383-418

De la Fuente Núñez, Rubén (2021), “El Establecimiento Provincial de Beneficencia de Segovia: desde sus orígenes hasta el inicio de la guerra civil española 1836-1936", Historia Social, (en prensa).

Echeverri Dávila, Beatriz (1991), La pandemia de gripe de 19181919 en España, Tesis Doctoral, Universidad Complutense de Madrid.

Echeverri Dávila, Beatriz (1993), La gripe española. La pandemia de 1918-1919, Madrid, CIS-Siglo XXI.

Echeverri Dávila, Beatriz (2003), "Spanish influenza seen from Spain". En: Phillips, Howard; Killingray, David (eds.), The Spanish influenza pandemic of 1918-1919. New perspectives, Londres, pp. 173-190.

Echeverri Dávila, Beatriz (2018), “En el centenario de la gripe española: un estado de la cuestión", Revista de Demografía Histórica, 36 (1), pp.17-42.

El Adelantado de Segovia, 1918-1919.

Elexpuru Camiruaga, Lucía (1986), La epidemia de gripe de 1918 en Bilbao. Estudio demográfico y estadístico, Salamanca, Ediciones Universidad de Salamanca.

Elexpuru Camiruaga, Lucía (1987), “Consecuencias demográficas de la epidemia gripal de 1918 en la villa de Bilbao", Homenaje al Dr. José María Basabe. Cuadernos de Sección Antropología-Etnográfica, San Sebastián: Eusko Ikaskuntza, pp. 267-277.

Erkoreka Barrena, Antón (2006), La pandemia de gripe española en el País Vasco 1918-1919, Bilbao, Universidad del País Vasco-BBK-Diputación Foral de Bizkaia.

Erkoreka Barrena, Antón (2009), “Origins of the Spanish Influenza pandemic (1918-1920) and its relation to the First World War", J Mol Genet Med, 3 (2), pp. 190-194.

Fernández Fernández, Carlos María; Veiga Ferreira, Xosé María (1995), "La gripe de 1918-19 en Betanzos", Anuario Brigantino, 18, pp. 143-158.

Frost W. H. (1919), "The epidemiology of Influenza”, Public Health Reports, 34, pp. 1823-1837.

García Delgado, José Luis; Sánchez Jiménez, José; Tuñón de Lara, Manuel (1984), "Los comienzos del siglo XX: población, economía y sociedad (1898-1930)". En: Jover Zamora, José María (dir.), Historia de España de Menéndez Pidal, Madrid, Espasa Calpe, tomo XXXVII.

García Durán, Román (1919), Memoria descriptiva y datos de la epidemia gripal padecida en la provincia de Valladolid en el año 1918, Universidad de Valladolid.

García-Faria Del Corral, Francisco Javier (1995), La epidemia de gripe de 1918 en la provincia de Zamora, Salamanca, Instituto de estudios zamoranos "Florián Ocampo"-Diputación de Zamora.

García Palomar, Félix (2003), “Epidemia de gripe en San Esteban de Gormaz durante 1918”, Celtiberia, 97, pp. 373-420.
Garrote Díaz, Juan Manuel (2001), Cien años de medicina en Segovia, Segovia, Colegio de Médicos de Segovia, Diputación Provincial y Caja Segovia.

González García, Alberto (2012), La epidemia de gripe de 19181919 en la provincia de Cuenca, Tesis Doctoral, Universidad de Castilla la Mancha.

González García, Alberto (2013), “Avances y tendencias actuales en el estudio de la pandemia de gripe 1918-1919", Vínculos de Historia, 2, pp. 309-330.

Granero Xiberta, Xavier (1981), “L'epidèmia de grip del 1918 a Barcelona", Actes del III Congrés D'Historia de la Medicina Catalana, 2, pp. 82-123.

Guenel, Jean (2004), “La grippe 'espagnole' en France en 1918 1919", Histoire des Sciences médicales, 38 (2), pp. 165-175.

Harvey Vaughan, Warren (1921): “Influenza: an epidemiological study", The American Journal of Hygiene, Monographic Series, 1.

Herrera Rodríguez, Francisco (1996), "Incidencia social de la gripe de 1918-1919 en la ciudad de Cádiz", Llull, 19, pp. 455-470.

Hoechling, A. A. (1961), The Great Epidemic, Boston.

Johnson, Niall; Mueller, Juergen (2002), “Updating the Accounts: Global Mortality of the 1918-1920 'Spanish' Influenza Pandemic", Bulletin of History of Medicine, 76, pp. 105-115.

Jordan, Edwin Oakes (1927), Epidemic Influenza, a Survey, Chicago.

Jorge, Ricardo (1919), La grippe, Lisbonne, Imprimerie Nationale.

Langford, Christopher (2002), The Age Pattern of Mortality in the 1918-19 Influenza Pandemic: An Attempted Explanation Based on Data for England and Wales, en Medical History, 46, pp. 1-20.

La Tierra de Segovia, 1918-1919.

Losada Álvarez, Juan Carlos (2003), "La Gripe Española: la epidemia más grave del siglo XX", La Aventura de la Historia, 56 , pp. $36-43$.

Martínez Fiol, David (2003), “La gripe española: la epidemia que vino de América", Clío: el pasado presente, 20, pp. 60-61.

Martínez Martín, Abel Fernando; Meléndez Álvarez, Bernardo Francisco; Manrique Corredor, Edward Javier (2014), "La junta central de higiene de Colombia, otra de las víctimas de la pandemia de gripa de 1918-1919", Astrolabio Nueva Época, 13, pp. 5-37.

Martínez Pons, Manuel (1995), La epidemia de gripe de 1918 en la ciudad de Valencia, Tesis Doctoral, Universidad de Valencia.

McNeill, Willian H. (1984), Plagas y pueblos, Madrid, Siglo XXI.

Ministry of health (1920), Report on the Pandemic of Influenza, London.

Montañá Buchaca, Daniel; Pujol i Ros, Joan (1998), “L'epidèmia de grip del 1918 el Principat d'Andorra", Revista de Historia de la Medicina y de las Ciencias de la Salud, 30, pp. 237-246. 
Oxford, J.; Lambkin, R.; Sefton, A.; Daniels, R.; Elliot, A.; Brown, R.; Gill, D. (2005), "A hypothesis: the conjunction of soldiers, gas, pigs, ducks, geese and horses in Northern France during the Great War provided the conditions for the emergence of the Spanish influenza pandemic of 1918-19", Vaccine, 23, pp. 940-945.

Palazón Fernando, Salvador (1991), "La pandemia de gripe de 1918-1920 y sus repercusiones en la mortalidad de la provincia de Alicante". En: Bernabéu-Meste, Josep (coord.), EI papel de la mortalidad en la evolución de la mortalidad valenciana, Alicante, Instituto de Cultura Juan Gil-Albert, 1991, pp. 89-98.

Patterson, K. David; Pyle, Gerald F. (1991), "The Geography and Mortality of the 1918 influenza Pandemic", Bulletin of the History of Medicine, 65 (1), pp. 4-21.

Pérez Moreda, Vicente (1980), La crisis de mortalidad en la España interior. Siglos XVI-XX, Madrid, Siglo XXI.

Phillips, Howard; Killingray, David (eds.) (2003), "Introduction". En: Spanish Influenza Pandemic of 1918-1919: New perspectives", London, Routledge.

Porpeta Llorente, Florencio (1918), Cartilla sanitaria contra la grippe o influenza, Madrid, imprenta de la casa editorial de M. Núñez Samper.

Porras Gallo, María Isabel (1994a), Una ciudad en crisis: la epidemia de gripe 1918-1919 en Madrid, Tesis Doctoral, Universidad Complutense de Madrid.

Porras Gallo, María Isabel (1994b), "La lucha contra las enfermedades evitables en España y la pandemia de gripe de 191819", Dynamis, 14, pp. 159-184.

Porras Gallo, María Isabel (1997), Un reto para la sociedad madrileña: la epidemia de gripe de 1918-1919, Madrid, Comunidad de Madrid-Editorial Complutense.
Porras Gallo, María Isabel (2008), "Sueros y vacunas en la lucha contra la pandemia de gripe de 1918-1919 en España", Asclepio, 60 (2), pp. 261-288.

Porras Gallo, María Isabel; Davis, Ryan A. (eds.) (2014), The Spanish influenza pandemic of 1918-1919. Perspectives from the Iberian Peninsula and the Americas, University of Rochester Press, Estados Unidos.

Porras Gallo, María Isabel (2018), "La pandemia de gripe de 1918-1919. El enemigo temido cien años después", Revista de Occidente, 448, pp. 95-106.

Rice, Geoffrey Wayne (2017), Black Flu 1918. The story of New Zealand's worst public health disaster, Canterbury University Press.

Sánchez de Val, Ángel (1919), La septicemia gripal: estudio clínico y terapéutico de la enfermedad pandémica conocida con el nombre de gripe española y desarrollada en Europa durante la segunda mitad del año de 1918, Madrid, Casa Editora.

Sánchez Fernández, Luis Vicente; Arcos González, Pedro; Neri Vela, Rolando; Hernández Martín, Elisa (2019), "La pandemia de gripe de 1918-1919 en territorio asturiano: de padecimiento histórico a enfermedad emergente cien años después". Revista cuatrienal de geografía, 39 (1), pp. 79-97.

Sánchez Gozalbo, Ángel (1919), Contribución al estudio de la gripe de 1918 en la provincia de Castellón, Castellón, Hijos de J. Armengot.

Tobías, José (1920), La epidemia de gripe de 1918-1919, Buenos Aires, Las Ciencias.

Trilla, Antoni; Trilla Guillem; Daer, Carolyn (2008): "The 1918 Spanish flu in Spain", Clin Infect Dis, 47 (5), pp. 668-673.

Tuells, José; Montagud Penadés, Emilia (2010), “Mujeres ante la gripe de 1918: la acreditación de las enfermeras", Vacunas: investigación y práctica, 1 (11), pp. 33-36. 